\title{
$\widehat{A}$ Madridge \\ madridge Journal of Case Reports and Studies \\ interconnec
}

Mini Review Article

Open Access

\section{The Blood Pressure Response to Stress in Female Nurses}

\author{
Lori J Alexander* \\ Associate Professor, Department of Nursing, Western Kentucky University, USA
}

\section{Article Info}

\author{
*Corresponding author: \\ Lori J Alexander \\ Associate Professor \\ Department of Nursing \\ Western Kentucky University \\ USA \\ Tel: 270-745-4078 \\ E-mail: lori.alexander@wku.edu
}

Received: September 10, 2018

Accepted: September 24, 2018

Published: September 29, 2018

Citation: Alexander LJ. The Blood Pressure Response to Stress in Female Nurses. Madridge J Case Rep Stud. 2018; 2(2): 71-73.

doi: $10.18689 /$ mjcrs- 1000118

Copyright: (c) 2018 The Author(s). This work is licensed under a Creative Commons Attribution 4.0 International License, which permits unrestricted use, distribution, and reproduction in any medium, provided the original work is properly cited.

Published by Madridge Publishers

\section{Introduction}

Much research has been conducted regarding stress, hypertension, and cardiovascular disease; however limited research has been conducted on the female population and is even more limited on female nurses. The physiological response to stress is different for females as compared to men and morbidity and mortality increases after menopause. This gap in research has occurred for many years with studies focusing on different variables regarding hypertension with prominent focus on the male population. At present there is limited research on stress and cardiovascular disease in women as their role becomes more demanding and challenging in today's society. "Most of our ideas about heart disease in women used to come from studying it in men". In a survey conducted by the American Heart Association (AHA), about half of the women interviewed knew that heart disease is the leading cause of death in women. Many mistakenly believe it is more common in men than women (American Heart Association [1]. With the majority of nurses being comprised of females, they are considered the primary stakeholder for this study. The implications of the findings are discussed in the context of the limited research currently available on the female nurse population.

Scientists and practitioners must be prepared to influence social change regarding the need for more research not only in females, but the female nurse population as well. With cardiovascular disease the leading cause of death in women, it is vital for scientifically social action to involve many parties, including the politician. However, there is a question regarding the necessity for research in this population due to the limited studies being conducted, therefore it is directly associated with the social and political arena. More research is needed on the blood pressure response to stress in the female nurse population due to nurses being the leading healthcare professional in the United States.

\section{System Problem}

In the history of the biomedical sciences, females have been limited in research studies and clinical trials. Some scientists consider the male to be representative of the human species while others seek to protect females from the adverse effects of drugs. Many studies of men will generate different results than women, specifically in response to drugs [2]. This has historically been seen in many studies of cardiovascular disease until 1993 when the National Institute of Health established guidelines for the inclusion of women and minorities in clinical research (S. Res. 107, 1993). This policy states that women and minorities must be included in all NIH funded clinical research, unless there is a sound reason or justification.

Presently in our health care system, single sex studies of males are still prominent in the literature and females are not included in many of the following disciplines: neuroscience, pharmacology, endocrinology, zoology, and physiology [2]. "In addition, 
many women say their physicians never talk to them about coronary risk and sometimes don't even recognize the symptoms, mistaking them instead for signs of panic disorder, stress, and even hypochondria" ("Harvard Health Publications, Health Newsletter," 2013, para. 5).

\section{Global Problem}

Global analysis of the worldwide concern of hypertension (HTN) revealed that $25 \%$ of the adults have HTN and $9.2 \%$ of total deaths are due to HTN related events [4]. In biomedical research, studies have shown differences in the questioning and treatment of female and male patients. This is not just a problem seen in the U. S., but is also an international concern. Most research on this subject has been about coronary heart disease and is seen internationally with a focus on the male population as well [5]. There has been limited research on the female population regarding stress and hypertension globally and even less evidence of research on female nurses regarding stress and hypertension.

\section{Social/Economic Concerns}

It is evident in the United States and the United Kingdom that increased mortality and morbidity is directly associated with lower socioeconomic status and is seen in developed as well as underdeveloped countries [6]. Social inequalities exist regarding research on the female nurse population in regards to stress and hypertension. This is evident in the literature review. It has been addressed in some studies that there is a"need for action that deals not simply with improved health care but also with the extremes of social inequality" [6]. There is a need to address certain risk factors as well as societal conditions and specifically the socioeconomic inequalities in cardiovascular disease. It has been proven that people classified as lower socioeconomic status will have higher blood pressure and higher risk of cardiovascular disease. With lower socioeconomic status, typically there is increased stress as well as poor lifestyle behaviors, poor diet, and lack of exercise.

Within the social context of this research, it is evident that there is a need for further research on the blood pressure response to stress in female nurses. Increased stress, or stimulation of the stress response, can lead to wear and tear on the heart and could increase the risk of hypertension and cardiovascular disease. It's important to study the effects of stress and how it effects this population in terms of biological, psychological, and sociocultural changes that could increase their risk.

\section{Ethical Issue}

Social justice and equality needs to be addressed regarding research in the female population. Research is now only beginning to unfold the differences in male vs. female population regarding stress and hypertension. Reasons for stress can vary for both males and females and can be from physical cause (illness or injury) or from a mental cause (marriage/divorce, familial, or job/career). In clinical studies, an "unjustified difference in the investigation and treatment of male and female patients" has been proven. It has been identified in the majority of research regarding males and cardiovascular disease but has also been seen in other studies as well. In several studies regarding other medical conditions such as kidney disease, HIV, colorectal cancer, COPD, and Parkinson's disease and thus, identifies a negative gender bias for females [5]. There is an ethical need for the study and treatment of the blood pressure response to stress in female nurses. This need is due to the female population not receiving the proper care for their conditions because those conditions haven't been studied in detail, or when they do receive care, it is based on inadequate information [3]. This is an injustice to our female population in general and is an ethical violation to researchers, clinicians, and scientists.

\section{Policy}

The NIH policy and guidelines on the inclusion of women and minorities as subjects in clinical research that was enacted in 1993 was a big step for the female population; however these guidelines only ensured $\mathrm{NIH}$ funded research to be carried out equally for both genders and diverse racial/ethnic groups (S. Res. 107, 1993). Many scientists and researchers presently continue to focus on the male population in clinical studies and research due to the Food and Drug Administration's (FDA) limiting guidelines. In Ethical and Legal Issues of Including Women in Clinical Studies states as follows:

that women of childbearing potential should be barred from large-scale (Phase III) clinical trials until all three segments of the FDA animal reproduction studies have been completed, and that women may be included in Phase II (controlled trials in several hundred subjects) studies only if "segment II and the female part of segment I of the FDA Animal Reproduction Guidelines have been completed." Segment I covers gonadal function, effects of estrous cycles/mating behavior, and early gestation; segment II, teratogenesis; and segment III, the drug's effect on late fetal development, labor and delivery, lactation, and newborn health,(1994).

These policies and guidelines were written initially to protect females and their unborn children, in clinical trials, that traditionally relates to medication. Policies need to address the inclusion of females in studies across the lifespan, specifically related to cardiovascular disease due to females being underrepresented throughout biomedical history.

\section{Conclusion}

In the current literature review, it was found that there was a gap/lack of evidence based studies in the female nurse population regarding the blood pressure response to stress, thus strengthening the necessity for this study to be conducted. Nurses comprise the majority of the healthcare professionals and it is typically a female dominated profession. This profession traditionally has an increased amount of stress and requires critical thinking skills autonomously.

By utilizing policy to change the current practice and include more females and female nurses in clinical studies and research regarding stress, hypertension, and cardiovascular disease (which is the leading cause of death in 
women) the gender bias in biomedical research can be reduced. It is vital for scientifically social action to involve many parties, including the legislator and improve overall health in the female population not only in the United States, but world-wide.

\section{References}

1. American Heart Association. Effectiveness-based guidelines for the prevention of cardiovascular disease in women-2011 update: A guideline from the american heart association. 2011.

2. Beery AK, Zucker I. Sex bias in neuroscience and biomedical research. $N \mathrm{H}$ S Public Access. 2011; 35(3): 565-572. doi: 10.1016/j.neubiorev.2010.07.002

3. Mastoianni AC, Faden R, Federman D. Ethical and legal issues of including women in clinical studies. Women and Health Research. 1994; 2: 127-150.
4. Mitwalli AH, Harthi AA, Mitwalli $H$, Juwayed AA, Turaif NA, Mitwalli MA. Awareness, attitude, and distribution of high blood pressure among health professionals. J Saudi Heart Assoc. 2012; 25(1): 19-24. doi: 10.1016/j. jsha.2012.10.002

5. Risberg G, Johansson E, Hamberg K. A theoretical model for analyzing gender bias in medicine. International Journal for Equity in Health. 2009; 8(28): 1-8. doi: 10.1186/1475-9276-8-28

6. Swales JD. Hypertension in the political arena. Journal of the American Heart Association. 2000; 35(6): 1179-1182. doi: 10.1161/01.hyp.35.6.1179 